\title{
Efficacy and mechanism of anti-tumor action of new potential CK2 inhibitors toward glioblastoma cells
}

\author{
BOZENA KAMINSKA ${ }^{1}$, ALEKSANDRA ELLERT-MIKLASZEWSKA ${ }^{1}$, AGATA OBERBEK ${ }^{1}$, \\ PAWEL WISNIEWSKI ${ }^{1}$, BEATA KAZA ${ }^{1}$, MALGORZATA MAKOWSKA ${ }^{2}$, \\ MARIA BRETNER ${ }^{2,3}$ and ZYGMUNT KAZIMIERCZUK ${ }^{4,5}$ \\ ${ }^{1}$ Laboratory Transcription Regulation, Nencki Institute, ${ }^{2}$ Institute of Biochemistry and Biophysics, Polish \\ Academy of Sciences; ${ }^{3}$ Chemistry Department, Warsaw University of Technology; ${ }^{4}$ Laboratory of \\ Experimental Pharmacology, Polish Academy of Sciences Medical Research Center; \\ ${ }^{5}$ Institute of Chemistry, Warsaw University of Life Sciences, Warsaw, Poland
}

Received May 14, 2009; Accepted July 10, 2009

DOI: 10.3892/ijo_00000424

\begin{abstract}
Malignant gliomas are highly resistant to current therapeutic approaches due to genetic alterations rendering them resistant to cell death. CK2, a ubiquitous and constitutively active serine/threonine kinase, frequently elevated in tumors, contributes to enhanced cell proliferation and resistance to apoptosis. Inhibition of CK2 expression or treatment with inhibitors of CK2 affected survival or induced apoptosis in various cancer cells. Here we compared cytotoxic effects of well-known and new CK2 inhibitors: 4,5,6,7-tetrabromo-1H-benzotriazole (TBB), 4,5,6,7tetrabromo-1H-benzimidazole (TBI), 2-dimethylamino4,5,6,7-tetrabromo-1H-benzimidazole (DMAT), the related 3-(4,5,6,7-tetrabromo-1H-benzimidazol-1-yl)propan-1-ol (MB001), 3-(4,5,6,7-tetrabromo-1H-1,2,3-benzotriazol-1-yl) propan-1-ol (MB002), 3-(4,5,6,7-tetrabromo-2H-1,2,3benzotriazol-2-yl)propan-1-ol (MB003) and also structurally similar to above compounds pentabromobenzylisothiourea (ZKK1) and its derivatives (ZKK2-8) on cultured malignant glioma cells. TBI, ZKK1 and MB001-3 were more effective
\end{abstract}

Correspondence to: Dr Bozena Kaminska, Laboratory of Transcription Regulation, The Nencki Institute of Experimental Biology, 3 Pasteur Str., 02-093 Warsaw, Poland

E-mail: bozenakk@nencki.gov.pl

Abbreviations: CK2, casein kinase 2; DMAT, 2-dimethylamino4,5,6,7-tetrabromo-1H-benzimidazole; PI3-kinase, phosphatidylinositol 3-kinase; PKB, protein kinase B (Akt); PTEN, phosphatase and tensin homolog deleted on chromosome ten; TBI, 4,5,6,7-tetrabromo-1H-benzimidazole; TBB , 4,5,6,7-tetrabromo1H-benzotriazole; ZKK1, pentabromobenzylisothiourea; MB001, 3(4,5,6,7-tetrabromo-1H-benzimidazol-1-yl)propan-1-ol; MB002, 3(4,5,6,7-tetrabromo-1H-1,2,3-benzotriazol-1-yl)propan-1-ol, MB003, 3-(4,5,6,7-tetrabromo-2H-1,2,3-benzotriazol-2-yl)propan-1-ol; BrdU, 5-bromodeoxyuridne

Key words: glioblastoma, casein kinase 2 inhibitors than TBB in inducing growth arrest and cell death in glioma cells. TBI and ZKK1 strongly induced apoptotic death involving caspase 3 and 7 activation followed by PARP cleavage. DMAT strongly upregulated the expression of cytotoxic ligand and its receptor Fas. Structural modifications of ZKK1 largely affected its efficacy: exchange of Br- to Clor F-substituents on the pentabromophenyl ring and inclusion of the bulky $\mathrm{N}$-phenyl substituent in thiourea fragment of ZKK1 diminished cytotoxic activity, while N-substitution with short alkyl groups or an allyl group had opposite effects. Interestingly, TBI at moderate dose did not affect viability of non-transformed astrocytes, suggesting some specificity toward tumor cells in cytotoxic action. TBI, DMAT and ZKK1-induced apoptosis associated with caspase cascade activation in human malignant glioblastoma cells with mutated PT53 and PTEN genes. The reported data demonstrate that suitably modified polybromobenzene molecules exhibit a significant cytotoxic potential towards malignant glioblastoma cells.

\section{Introduction}

Gliomas are the third most frequent cause of cancer-related deaths in adults and the second most in children. Despite numerous advances in chemotherapeutic, radiation and surgical procedures, the survival rate for patients with gliomas/ glioblastomas has remained unchanged for the past 30 years and a chance of two-year survival for patients with WHO grade IV glioblastoma multiforme is less than $30 \%(1,2)$. Even combination of treatment regiments is ineffective, because resistant tumor cells infiltrate normal brain tissue, so that tumor recurrence is inevitable. Frequent deficiencies in death ligand/receptor signaling, cyclin dependent kinase inhibitors, mutations in genes coding for tumor suppressors: PTEN, TP53 greatly limit an efficacy of current treatments and call for the development of novel therapeutic approaches overcoming the resistance of glioblastoma cells (4-6).

CK2 (casein kinase 2) is the most pleiotropic of all protein kinases with more than 300 substrates implicated in a wide variety of cellular functions in gene expression, signal 
transduction, proliferation and cell survival (7-9). Antisense oligonucleotides against CK2 $\alpha$ or CK2 $\beta$ (10), microinjection of anti-CK2 antibodies or inhibitors of CK2 (11-14) inhibit cell cycle progression. Elevated CK2 activity has been demonstrated in a number of cancers and shown to regulate the activity of various oncoproteins and tumor suppressor proteins. Development of CK2 inhibitors is ongoing in preclinical studies, resulting in the generation of a number of CK2-directed compounds (reviewed in refs. 9,14,15). Some of these inhibitors such as 4,5,6,7-tetrabromo-1Hbenzimidazole (TBI) and 2-dimethylamino-4,5,6,7tetrabromo-1H-benzimidazole (DMAT) inhibited the growth of malignant lymphoblastic leukemia cells with a better efficiency than Imatinib, the well-known tyrosine kinase inhibitor (16-18). Downregulation of CK2 activity with specific inhibitors or silencing of CK $2 \alpha$ expression induced cell death in drug-resistant R-CEM cells, overcoming the multidrug resistance phenotype $(19,20)$. Inhibition of CK2 with $100 \mu \mathrm{M}$ TBB or 20-40 $\mu \mathrm{M}$ DMAT significantly decreased viability and induced apoptosis of three human colon cancer and breast cancer cells in vitro (21). Furthermore, the CK2 specific inhibitors 5,6-Dichloro-1- - -D ribofuranosylbenzimidazole and Apigenin induced apoptosis in pancreatic cancer cells (22), and hormone-sensitive prostate cancer cells (23). DMAT induced caspase-mediated killing of human breast cancer MCF-7 cells (24) suggesting a broad spectrum of vulnerable cancer cells.

The two most widely used cell permeable CK2 inhibitors are TBB and DMAT, the latter one displays the lowest K(i) value reported for a CK2 inhibitor $(40 \mathrm{nM})$ and its efficacy in endogenous CK2 inhibition was reported several-fold higher than TBB (25-27). Protein kinase CK2 is abundant in rat brain when compared with other rat tissues (28) and our unpublished data suggest elevated level of CK2 in glioma cells vs. non-transformed astrocytes. CK2 is involved in phosphorylation of the tumor suppressor PTEN in vitro and in glioblastoma cells, DMAT $(20 \mu \mathrm{M})$ reduced PTEN phosphorylation in glioblastoma cell lines (29).

In the present study, we evaluated the cytotoxic efficacy of widely used CK2 inhibitors $(25-27,30)$, as well as newly synthesized compounds of MB001-3 (31) and ZKK1-8 series on cultured glioblastoma cells and non-transformed glial cells. We determined molecular pathways involved in the induction of cell death following treatments. Furthermore, we determined drug effects on different human malignant glioblastoma cell lines with mutated TP53 and/or PTEN tumor suppressors, highly resistant to radiation and majority of anticancer drugs. The results described here demonstrate for the first time the promising antitumor efficacy of newly synthesized CK2 inhibitors and provide insights into molecular mechanism of their toxic action.

\section{Materials and methods}

Synthesis. Chemicals: The 4,5,6,7-tetrabromo-1H-benzimidazole (TBI) and 4,5,6,7-tetrabromo- $1 H$-benzotriazole (TBB) were obtained by excessive bromination of $1 H$-benzimidazole or $1 H$-benzotriazole as described $(32,33)$. DMAT was synthesized according to Pagano et al (34). MB001-3 were obtained by alkylation of TBI or TBB as published (31).
2,3-Dichlorobenzylizothiourea (ZKK7) was obtained according to Iwai et al (35), the compounds ZKK1-6 and ZKK8 were synthesized according to the following procedure: to the hot solution of respective thiourea $(1 \mathrm{mmol})$ in anh. ethanol $(20 \mathrm{ml})$ pentabromobenzyl-(for ZKK1-6) or pentafluorobenzyl-(for ZKK8) bromide $(1.1 \mathrm{mmol})$ was added. The reaction mixture was stirred and refluxed for $20 \mathrm{~min}$. Next, it was concentrated to $15 \mathrm{ml}$ and left to crystallize. White crystals of chromatographic pure compounds were obtained. For analytical and biological purposes small samples were crystallized from anh. ethanol. Melting points and yields were as follows: ZKK1, 273-276 ${ }^{\circ} \mathrm{C}(73 \%)$; ZKK2, 266-268 ${ }^{\circ} \mathrm{C}$ (88\%); ZKK3, 242-244 ${ }^{\circ} \mathrm{C}(85 \%) ; \mathrm{ZKK} 4,229-231^{\circ} \mathrm{C}(77 \%)$; ZKK5, 250-252 ${ }^{\circ} \mathrm{C}(75 \%)$; ZKK6, $243^{\circ} \mathrm{C}(72 \%)$ and ZKK8, $201-203^{\circ} \mathrm{C}(84 \%)$. 1H-NMR spectra and elemental analyses are available from the authors upon request.

Cell cultures and treatments. The rat C6 glioma cell line and the human cell lines: T98G (derived from a glioblastoma multiforme, WHO grade IV), LN229 (derived from an astrocytoma WHO grade III) were from ATCC. Cells were cultured in Dulbecco's modified Eagle's medium supplemented with $10 \%$ fetal bovine serum (Sigma) and antibiotics $(50 \mathrm{U} / \mathrm{ml}$ penicillin, $50 \mu \mathrm{g} / \mathrm{ml}$ streptomycin). Cells were grown in 24-well plates or 10 -cm diameter culture plates (Corning) in a humidified atmosphere of $\mathrm{CO}_{2} /$ air $(5 / 95 \%)$ at $37^{\circ} \mathrm{C}$. Primary cultures of cortical astrocytes were prepared from cortices of newborn rats as previously described (36). Astrocytes were plated on poly-L-lysine-coated 24-well culture plates $\left(7 \times 10^{4}\right.$ of cells per well) and maintained in DMEM with Glutamax (Sigma) containing 10\% fetal bovine serum and $1 \%$ antibiotics. Cells were treated with specific compounds dissolved in DMSO or DMSO at the corresponding concentrations $18 \mathrm{~h}$ after plating. The effects of the compounds were monitored at various time points by phase-contrast microscopy.

Proliferation assay. BrdU incorporation test was used to determine the cell proliferation rate. Briefly, C6 glioma cells $\left(1 \times 10^{6}\right.$ cells/well) were seeded onto a $24-w e l l$ plate, cultured for $18 \mathrm{~h}$, then the treatment (DMSO or various drugs) was applied for $18 \mathrm{~h}$. BrdU $(10 \mu \mathrm{M})$ was added to the culture medium and cells were incubated for $6 \mathrm{~h}$. Subsequently, cells were fixed and the level of BrdU incorporation was determined according to the manufacturer's protocol (Cell Proliferation ELISA BrdU assay, Roche Diagnostics GmbH Mannheim, Germany).

Cell viability (MTT metabolism assay). Cells were cultured in 96-well plates with the addition of the indicated concentrations of CK2 inhibitors or DMSO. MTT stock solution (Sigma-Aldrich) was added to each well to a final concentration of $0.5 \mathrm{mg} / \mathrm{ml}$. After $4 \mathrm{~h}$ of incubation at $37^{\circ} \mathrm{C}$ waterinsoluble dark blue formazan crystals were dissolved in lysis buffer containing 20\% SDS and 50\% DMF. Optical densities were measured at $570 \mathrm{~nm}$ using a scanning multiwell spectrophotometer. All measurements were carried out in triplicate.

Western blot analysis. Cells were collected in PBS (phosphate-buffered saline) with protease inhibitors (1 $\mathrm{mM}$ 
PMSF, $10 \mu \mathrm{g} / \mathrm{ml}$ aprotinin and leupeptin, $0.7 \mu \mathrm{g} / \mathrm{ml}$ pepstatin A) and total protein extracts were prepared mixed with $2 \mathrm{X}$ Laemmli sample buffer followed by boiling for $15 \mathrm{~min}$. After centrifugation at $15,000 \mathrm{rpm}$ for $15 \mathrm{~min}$ at $4^{\circ} \mathrm{C}$, protein samples were resolved by SDS-PAGE and transferred to nitrocellulose membranes (Amersham). Equal protein loading was confirmed by staining the membranes with Ponceau Red (Sigma). Phosphorylation of Rb (Retinoblastoma protein) was determined with antibody recognizing Ser780 phospho$\mathrm{Rb}$ (Cell Signaling, USA). Caspase activation was evaluated by Western blot analysis in cell extracts using specific antibodies recognizing total (p57) and cleaved (p43/41) caspase 8, total (p59) and cleaved (p37) caspase 9, cleaved caspases: p20 (caspase 7), p19/p17 (caspase 3) and p116 and p89 for PARP (Cell Signaling) as described $(37,38)$. Membranes were incubated with primary antibodies diluted in TBS-T (10 mM Tris/HCl, pH 7.6, $0.12 \mathrm{M} \mathrm{NaCl,} \mathrm{0.1 \%}$ Tween-20 and $0.05 \%$ sodium azide) containing $5 \%$ skimmed milk. Antibody recognition was detected with the anti-rabbit IgG secondary antibody linked to horseradish peroxidase (Cell Signaling). ß-actin was detected using monoclonal anti$\beta$-actin, peroxidase-linked antibody (Sigma). Immunocomplexes were visualized using enhanced chemiluminescence detection system (ECL, Amersham).

Analysis of mitochondrial membrane potential $(\Delta \Psi)$. The mitochondrial membrane potential was analyzed using flow cytometry as previously described (37). Briefly, the cells were harvested at $24 \mathrm{~h}$ post-treatment, resuspended in complete culture medium, adjusted to a density of $0.5 \times 10^{6}$ cells $/ \mathrm{ml}$ and incubated with $5 \mu \mathrm{M}$ JC-1 (5,5',6,6'-tetrachloro-1,1',3,3'tetraethylbenzimidazole-carbocyanine iodide, Molecular Probes, USA) for $15 \mathrm{~min}$ at $37^{\circ} \mathrm{C}$ in the dark. Stained cells were washed twice in cold PBS, suspended in $500 \mu 1$ of KRHEPES buffer (121 mM NaCl, $25 \mathrm{mM}$ HEPES, $5 \mathrm{mM}$

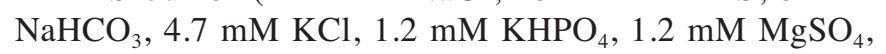
$2 \mathrm{mM} \mathrm{CaCl}_{2}, 10 \mathrm{mM}$ glucose, $\mathrm{pH}$ 7.4) and analyzed on a FACScalibur flow cytometer using CellQuest software (both from Becton-Dickinson). Additionally, a sample of JC-1 loaded cells was incubated with the uncoupling agent carbonyl cyanide $m$-chloro-phenylhydrazone (CCCP; $10 \mu \mathrm{M}$; Sigma) as a positive control. As the JC-1 dye exhibits potential-dependent accumulation in the mitochondrial matrix indicated by a fluorescence emission shift, red and green fluorescence was acquired through 585/42-nm (FL2) and 530/30-nm (FL1) bandpass filters, respectively. The FL2/FL1 ratios of mean fluorescence intensities were calculated for each cell sample and normalized to FL2/FL1 ratio of the DMSO control.

RNA isolation and PCR analysis. Total RNA was isolated according to manufacturer's protocol (Qiagen), including a DNase digestion step. cDNAs were synthesized by extension of oligo $(\mathrm{dT})_{15}$ primers with 200 units of M-MLV reverse transcriptase in a mixture containing $1 \mu \mathrm{g}$ of total RNA in $20 \mu 1$. The expression of Fas and FasL was evaluated by a quantitative real-time PCR using the 7500 real-time PCR System (Applied Biosystems); amplification of rat $18 S$ rRNA in the same samples served as the internal control. Reaction volume $(20 \mu \mathrm{l})$ consisted of cDNA equivalent to $50 \mathrm{ng}$ RNA,
A<smiles>Brc1c(Br)c(Br)c2[nH]nnc2c1Br</smiles><smiles>Brc1c(Br)c(Br)c2c(c1Br)NCN2</smiles><smiles>CN(C)c1nc2c(Br)c(Br)c(Br)c(Br)c2[nH]1</smiles><smiles></smiles><smiles>CCCCCCn1nnc2c(Br)c(Br)c(Br)c(Br)c21</smiles><smiles></smiles><smiles>NC(=[NH2+])SCc1c(Br)c(Br)c(Br)c(Br)c1Br</smiles>
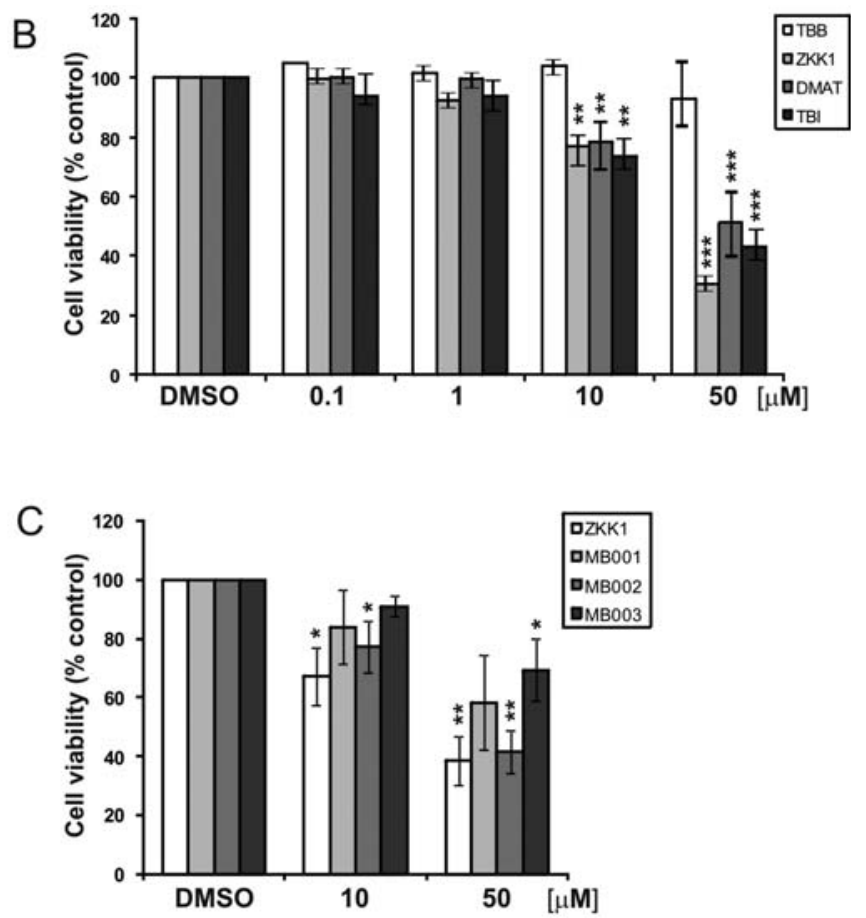

Figure1. Biological effects of CK2 inhibitors on viability of cultured glioma cells. (A) Chemical structure of known and novel CK2 inhibitors: 4,5,6,7tetrabromobenzotriazole (TBB), TBB derivatives (MB001-3), 4,5,6,7 tetrabromo-1H-benzimidazole (TBI), 2-dimethylamino-4,5,6,7-tetrabromo1H-benzimidazole (DMAT), pentabromobenzylisothiourea (ZKK1). Rat C6 glioma cells were cultured as described. Cytotoxic effects of newly developed compounds or $0.5 \%$ DMSO were determined $24 \mathrm{~h}$ after the treatment. (B and C) MTT metabolism rate measured as optical density at $570 \mathrm{~nm}$ is proportional to the number of living cells after exposure to indicated concentrations of compounds. Results are expressed in values relative to DMSO-treated control cells and represent the mean \pm SEM of three independent experiments, each in triplicates; ${ }^{* * *} \mathrm{p}<0.005,{ }^{* *} \mathrm{p}<0.01$ and ${ }^{*} \mathrm{p}<0.05$.

1x SYBR Green PCR master mix (Applied Biosystems) and $0.9 \mu \mathrm{M}$ of each primer. The following primers were used: rat $18 S$ sense (5'-GTAACCCGTTGAACCCCATT-3'), antisense (5'-CCATCCAATCGGTAGTAGCG-3'); rat Fasl sense (5'-C CAACCACAGCCTTAGAGTATCATC-3'), antisense (5'-C 
A

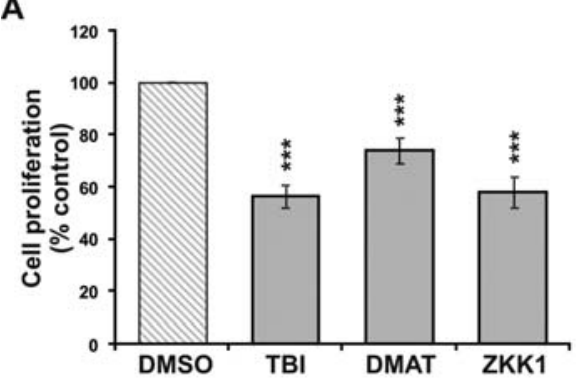

B

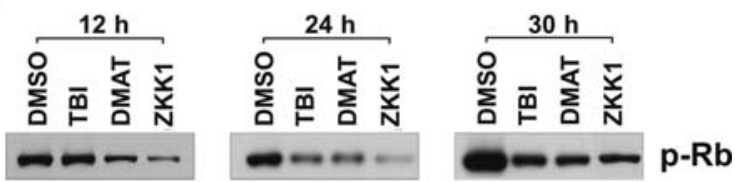

Figure 2. Effects of TBI, DMAT and ZKK1 on proliferation of C6 glioma cells. (A) The effects of compounds (drugs at concentration $50 \mu \mathrm{M}$ or corresponding dose of DMSO, $0.2 \%$ ) on the proliferation of C6 glioma cells was assessed by BrdU incorporation test. (B) Representative immunoblot shows changes in the level of phosphorylated $\mathrm{Rb}$, determined in total protein extracts collected 12,24 and $30 \mathrm{~h}$ after treatment with drugs or $0.2 \%$ DMSO. Similar results were reproduced in two other experiments.

CCTGTTAAGTGGGCCACACT-3'); rat Fas sense (5'-TTG GAAGGCCTGCATCATG-3'), antisense (5'-CAGTCTGGT TCATCCCCATTG-3').

The thermal cycling conditions were as follows: $50^{\circ} \mathrm{C}$ for $2 \mathrm{~min}, 95^{\circ} \mathrm{C}$ for $10 \mathrm{~min}$, followed by 40 cycles of $15 \mathrm{sec}$ at $95^{\circ} \mathrm{C}$ for denaturation and $1 \mathrm{~min}$ at $60^{\circ} \mathrm{C}$ for annealing and extension. The specificity of the PCR reaction was confirmed by a single peak in a dissociation curve. $\mathrm{Ct}$, the threshold cycle, was determined after automatic setting the threshold in the linear amplification phase of the PCR reaction and averaged for each sample assayed in duplicates. Fold change was calculated as $2^{-\Delta \Delta C t}$.

Statistical analysis. Data are presented as mean \pm SEM and were analyzed by ANOVA followed by Newman-Keuls test using Statistica software as indicated. Differences were considered statistically significant for $\mathrm{p}<0.05$.

\section{Results}

Novel CK2 inhibitors potently affect proliferation and induce cell death in cultured glioma cells. Fig. 1 shows the structure of tested compounds. We compared the biological effects of well known CK2 inhibitors: 4,5,6,7-tetrabromo-1H-benzotriazole [TBB, $\mathrm{IC}_{50} 0.5 \mu \mathrm{M}$, (39)] and the related 4,5,6,7tetrabromo-1H-benzimidazole [TBI $\mathrm{IC}_{50} 0.5 \mu \mathrm{M}$, (39)] with an influence of recently developed 2-dimethylamino-4,5,6,7$1 \mathrm{H}$-tetrabromobenzimidazole (DMAT IC $\left.{ }_{50} 0.14 \mu \mathrm{M}(39)\right], \mathrm{N}-$ hydroxypropyl analogs MB001-3 [ $\left.\mathrm{IC}_{50} 0.3-0.5 \mu \mathrm{M}(31)\right]$ and pentabromobenzylisothioureas $\left(\mathrm{ZKK} 1-8 \mathrm{IC}_{50} 7-50 \mu \mathrm{M}\right.$, unpublished results) on growth and survival of cultured glioblastoma cells (Fig. 1). Cytotoxic effects of newly developed compounds were determined using MTT metabolism test $24 \mathrm{~h}$ after the treatment. While TBB did not affect
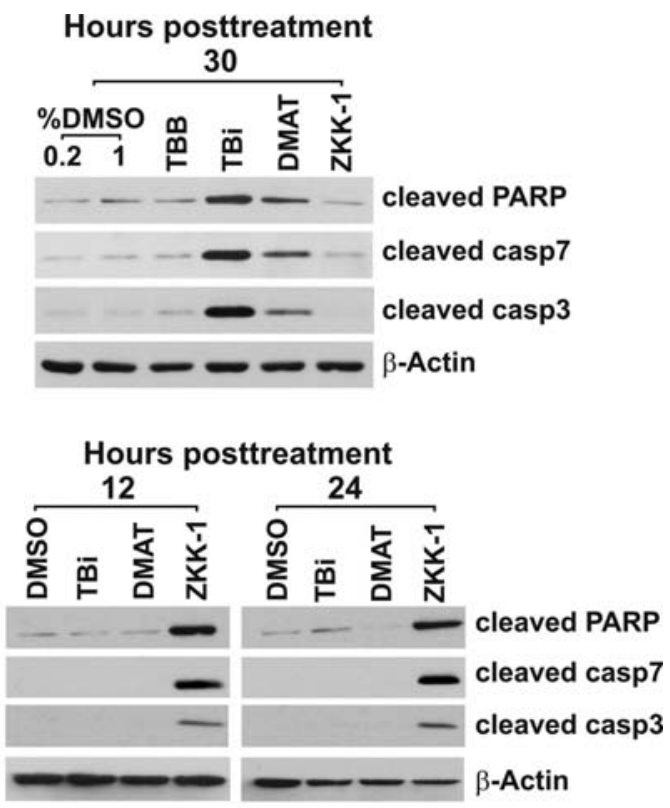

Figure 3. Induction of apoptotic caspase cascade in drug-treated C6 glioma cells. Effects of different compounds were determined 12, 24 and $30 \mathrm{~h}$ after the treatment; corresponding doses of DMSO $(0.2$ or $1 \%)$ were added to control cultures. Activation of caspase 7, caspase 3 and PARP proteolysis was determined by immunodetection of cleaved proteins. C6 glioma cell extracts were prepared as described in Materials and methods. Western blot analysis was performed using antibodies recognizing cleaved caspase 3 and caspase 7, cleaved PARP. Blots were re-probed with antibody recognizing $\beta$-actin to ensure equal protein loading.

the number of living cells, TBI and new reagents effectively reduced the viability of $\mathrm{C} 6$ glioma cells. The most effective was ZKK1 treatment leading to cell death of approximately $50-70 \%$. Treatment for $48 \mathrm{~h}$ resulted in a massive cell death in over $70 \%$ of the cells. MTT metabolism test allows to quantify changes in the number of living cells without resolving if drug treatment affects cellular proliferation or viability, thus next we determined the effects of compounds at concentration $50 \mu \mathrm{M}$ or $0.2 \%$ DMSO on the proliferation of C6 glioma cells using BrdU incorporation test. As shown in Fig. 2A, TBI, DMAT and ZKK1 with a similar efficacy reduced the BrdU incorporation during DNA synthesis.

Cytostatic activities of these drugs were confirmed by their ability to reduce the level of phosphorylated Rb (Fig. 2B). The retinoblastoma protein $(\mathrm{pRb})$ acts to constrain the G1-S transition in mammalian cells. Most documented RB activity is the repression of the E2F family of transcription factors, which regulate the expression of genes involved in cell proliferation and survival (40). Phosphorylation of $\mathrm{pRb}$ in G1 inactivates its growth-inhibitory function, allowing for cell cycle progression (41). Decrease of $\mathrm{pRb}$ phosphorylation induces G1 growth arrest. Treatment with TBI, DMAT and ZKK1 resulted in a decrease of the level of phosphorylated $\mathrm{Rb}$ consistent with the induction of growth arrest. It is noteworthy that the strongest reduction of $\mathrm{Rb}$ phosphorylation was observed in ZKK1 treated cells (Fig. 2B).

Phase-contrast micrographs showed that $\mathrm{C} 6$ cells exposed for $24 \mathrm{~h}$ to TBI, DMAT or ZKK1 showed typical apoptotic changes in cellular morphology: retraction of cell extensions, cell shrinkage, membrane blebbing consistent with ongoing 
A

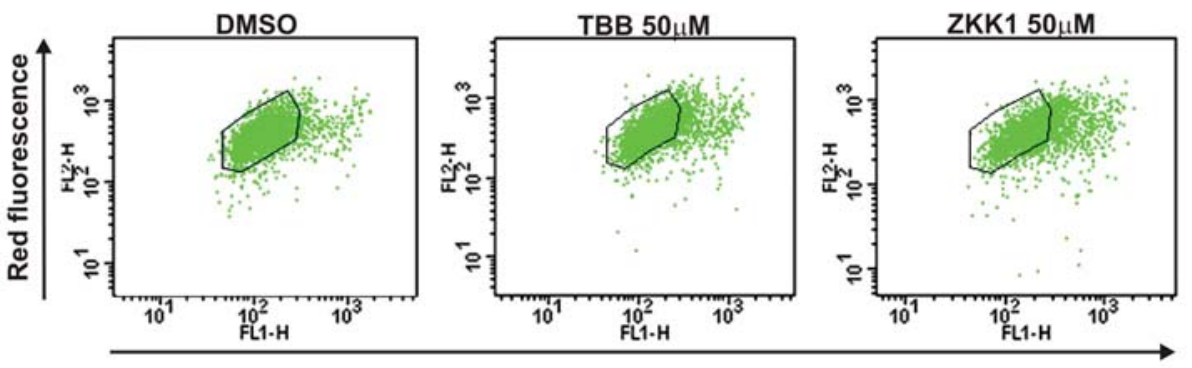

Green fluorescence

B

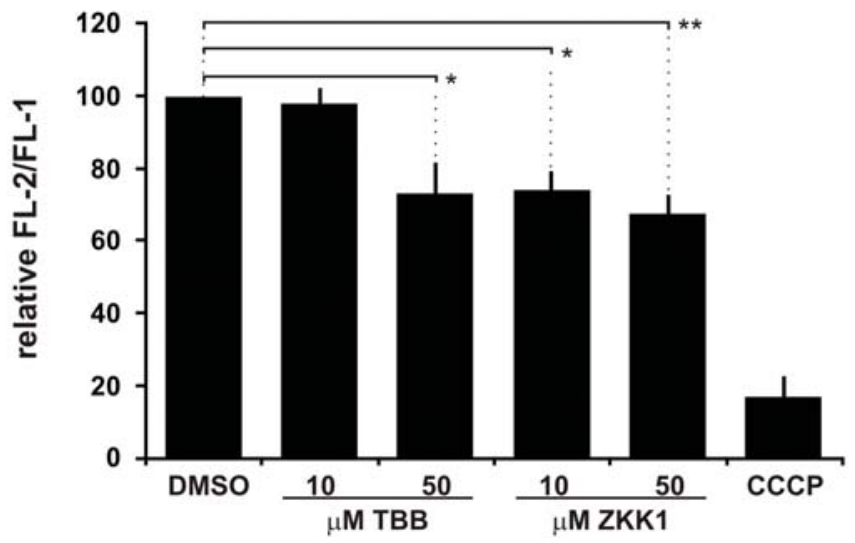

Figure 4. Analysis of mitochondrial transmembrane potential in drug-treated C6 glioma cells. (A) Mitochodrial membrane potential was evaluated by flow cytometry $24 \mathrm{~h}$ after treatment. Representative histograms of control (DMSO, 0.2\%), TBB and ZKK1-treated cells. Glioma cells were stained with the fluorescent probe JC-1 after the treatment with inhibitors; cells treated with the uncoupling agent CCCP for 10 min served as a positive control for mitochondrial depolarization. An enhancement of the green fluorescence and reduction of the red fluorescence, are presented as shifts in FL-1 and FL-2 channel intensities, respectively. (B) Change of the red/green fluorescence intensity ratio, normalized by the values from untreated controls (relative FL-2/FL-1), indicates a statistically significant loss of mitochondrial membrane potential after $24 \mathrm{~h}$ exposure $\left({ }^{*} \mathrm{p}<0.05\right.$ and $\left.{ }^{* *} \mathrm{p}<0.01\right)$ as compared to control, DMSO treated cells. Bars represent the mean \pm SEM from 3 independent experiments.

apoptotic cell death. The enhanced apoptosis by TBI, DMAT and ZKK1 was confirmed by nuclear staining with DAPI visualizing morphological alterations of cell nuclei (not shown). The apoptotic cell-death is executed through activation of intracellular proteinases, known as caspases that results in cleavage of caspase substrates, and finally cell demise (42-44). We evaluated activation of caspase 7 , caspase 3 and PARP proteolysis by immunodetection of cleaved proteins. C6 glioma cells were treated with $50 \mu \mathrm{M}$ TBI, DMAT and ZKK1 for various times (Fig. 3). As shown in Fig. 3, a strong activation of excecutory caspases 3 and 7, as well as accumulation of cleaved PARP occurred in TBI and DMAT-treated cells $30 \mathrm{~h}$ post-treatment. ZKK1 induced activation of caspases much faster than other compounds: accumulation of cleaved caspases 3 and 7, and PARP was observed at 12-24 h.

Determining of mechanisms of cell death induced by novel CK2 inhibitors in glioblastoma cells. There are two major and characterized apoptotic pathways leading to caspase cascade; 'intrinsic' and 'extrinsic' (45-47). In the extrinsic pathway, the apoptotic machinery is triggered by the interaction of death ligands of the tumor necrosis factor (TNF) family (such as Fas/CD95 ligand and TNF-related apoptosis-inducing ligand (TRAIL)/Apo2L) with their corresponding death

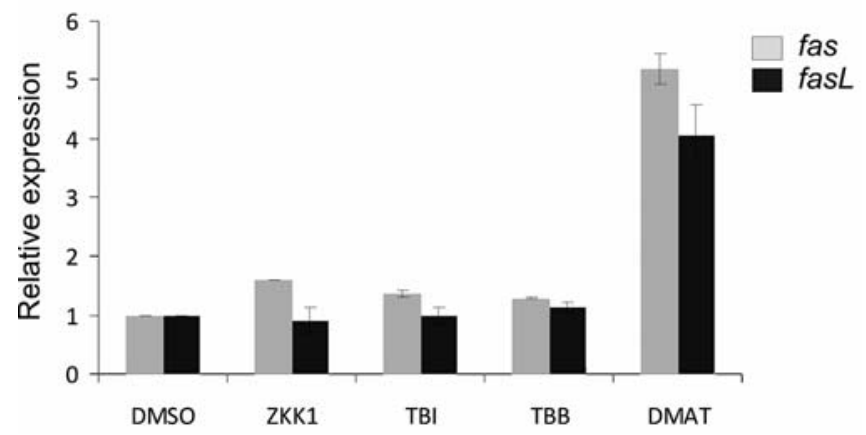

Figure 5. Expression of fasl and fas in drug-treated C6 glioma cells. Rat C6 glioma cells were treated with different drugs at concentration $50 \mu \mathrm{M}$ or corresponding dose of DMSO. Twenty-four hours after treatment cells were lyzed and total RNA was isolated. The expression level of fasl and fas was determined using real-time PCR and relative quantification; determination of 18S RNA expression served as an internal control. Bars represent the mean \pm SEM from 2 independent experiments, each in duplicate.

receptors (such as Fas/CD95, DR4 and DR5) (45). The intrinsic apoptotic pathway involves alterations in mitochondrial membrane, release of cytochrome c to the cytosol, apoptosome formation, activation of initiatory caspases and further activation of executory caspases. 
Flow cytometric analysis was employed to study alterations of mitochondrial transmembrane potential in control and CK2 inhibitors-treated C6 glioma cells stained with the fluorescent probe JC-1. Cells treated with the uncoupling agent CCCP for 10 min served as a positive control for mitochondrial depolarization. Fig. 4 shows representative histograms of DMSO, TBB and ZKK1 treated cells. Change of the red/green fluorescence intensity ratio indicates a loss of mitochondrial membrane potential $24 \mathrm{~h}$ after exposure. Treatment with 10 and $50 \mu \mathrm{M}$ ZKK1 resulted in statistically significant alterations of mitochondrial membrane potential, while in TBB-treated cells, only at the $50 \mu \mathrm{M}$ a loss of mitochondrial membrane potential was observed (Fig. 4). TBI and DMAT showed similar potency to modulate a mitochondrial membrane potential as ZKK1 (not shown).

To elucidate extrinsic apoptotic pathways we determined the expression of Fas and its ligand in C6 glioma cells $24 \mathrm{~h}$ after treatment with $50 \mu \mathrm{M}$ TBI, TBB, ZKK1 and DMAT. The levels of fasl and fas mRNA were determined by quantitative real-time PCR. In contrast to other compounds, DMAT induced a strong increase of both fas and fasl mRNA in treated C6 glioma cells (Fig. 5).

Generation of $Z K K$ derivatives to improve its inhibitory properties. Since ZKK1 showed strong cytotoxic and proapoptotic effects, we sought to determine whether its inhibitory properties can be improved. The ZKK1 derivatives were obtained in the reaction of pentabromobenzylbromide with $\mathrm{N}$-substituted thiourea derivatives (Fig. 6A). The most efficient inhibitors were isothioureas carrying methyl or dimethyl (ZKK2-3) and ethyl or allyl groups (ZKK4-5). The viability of cells treated with ZKK2-5 dropped on average by $30-60 \%$ at doses 10 and $50 \mu \mathrm{M}$, respectively, after $24 \mathrm{~h}$ of treatment (Fig. 6B). The viability of treated cells was further reduced after 2 days of treatment with ZKK2-5. Isothioureas carrying $\mathrm{Cl}$ or $\mathrm{F}$ substituents on the phenyl ring showed low or hardly any cytotoxic activity (ZKK7-8) when compared to ZKK1 (Fig. 6B and C).

Effects of novel CK2 inhibitors on proliferation and survival of non-transformed glial cells. Furthermore, we studied effects of ZKK1 and TBI at the concentration range of 0.1-50 $\mu \mathrm{M}$ on viability of non-transformed, primary astrocyte cultures 24 and $48 \mathrm{~h}$ after the treatment (Fig. 7). While 10 and $50 \mu \mathrm{M}$ ZKK1 strongly reduced a viability of astrocytes by over $50 \%$, these cultures were relatively resistant to exposure to 10 and $50 \mu \mathrm{M}$ TBI for $24 \mathrm{~h}$. A prolonged treatment with $50 \mu \mathrm{M}$ TBI resulted in $20 \%$ reduction of astrocyte viability. The results demonstrate that non-transformed glial cells show similar vulnerability to treatment with ZKK1 as C6 glioma cultures, but are more resistant to TBI.

Cytotoxic efficacy of novel CK2 inhibitors towards cultured human glioblastoma cells. Multiple molecular mechanisms involved in drug resistance of human glioblastoma cells have been described, including frequent alterations in genes coding for tumor suppressors: PTEN and TP53, that result in reduced sensitivity to anticancer drugs $(48,49)$. To study drug effects on human glioblastoma cells, we selected two cell lines: T98G deficient in functional PTEN and TP53 and LN229 with mutated TP53.
A

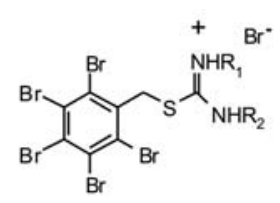<smiles></smiles>

ZKK

$1 R_{1}, R_{2}=H$

$2 \mathrm{R}_{1}=\mathrm{CH}_{3}, \mathrm{R}_{2}=\mathrm{H}$

$3 \mathrm{R}_{1}, \mathrm{R}_{2}=\mathrm{CH}_{3}$

$4 \mathrm{R}_{1}=\mathrm{C}_{2} \mathrm{H}_{5}, \mathrm{R}_{2}=\mathrm{H}$

$5 R_{1}=$ allyl, $R_{2}=H$

$6 R_{1}=$ phenyl, $R_{2}=H$ $7 \mathrm{R}_{1,4,5}=\mathrm{H}, \mathrm{R}_{2,3}=\mathrm{Cl}$
$8 \mathrm{R}_{1,5}=\mathrm{F}$

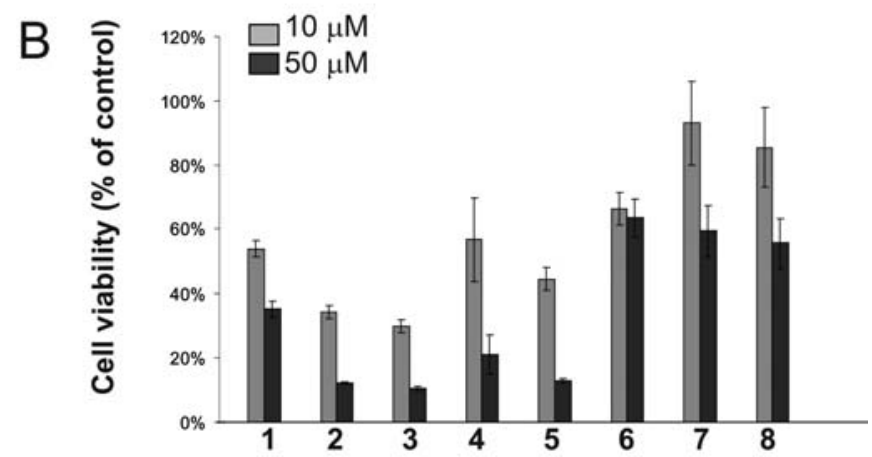

C

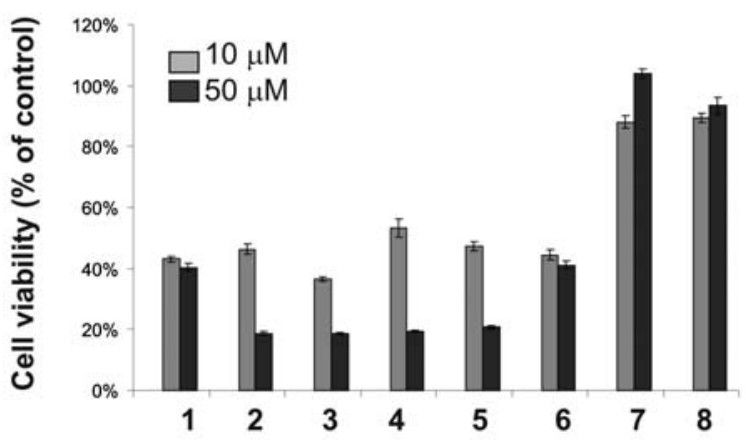

Figure 6. Structure and biological effects of ZKK1 derivatives on viability of C6 glioma cells. (A) Structure of halogenated benzylisothiourea derivatives of ZKK. (B) C6 glioma cells were cultured as described. Cytotoxic effects of newly developed compounds were determined 24 and $48 \mathrm{~h}$ after the treatment; corresponding doses of DMSO (0.2 or $1 \%)$ were added to control cultures. MTT metabolism was measured as optical density at $570 \mathrm{~nm}$. Results are expressed in values relative to DMSO-treated cells and correspond to the mean \pm SEM of three independent experiments, each in triplicate. Note the enhanced cytotoxic activity of some ZKK1 derivatives.

We demonstrate that human LN229 glioblastoma cells were moderately resistant to TBB and DMAT treatment, while TBI and ZKK1 exerted cytotoxic effect and reduced cell viability by $40 \%$, when applied at concentration of $50 \mu \mathrm{M}$. T98G cells were totally resistant to TBB and DMAT, but TBI and ZKK1 were effectively cytotoxic at concentration of $50 \mu \mathrm{M}$. Interestingly, ZKK1 was effective even at $10 \mu \mathrm{M}$ (Fig. 8A). Immunoblots demonstrate that TBI, DMAT and ZKK1 strongly activate executory caspases 3 and 7, and the regulatory caspase 8 in cells treated for $12-24 \mathrm{~h}$. In T98G cells, TBI and DMAT clearly activated caspases 3, 7 and 8, while ZKK1 did not activate these caspases. In contrast to other tested compounds, in both cell lines TBI induced accumulation of active caspase 9, known to be involved in 
$24 \mathrm{~h}$

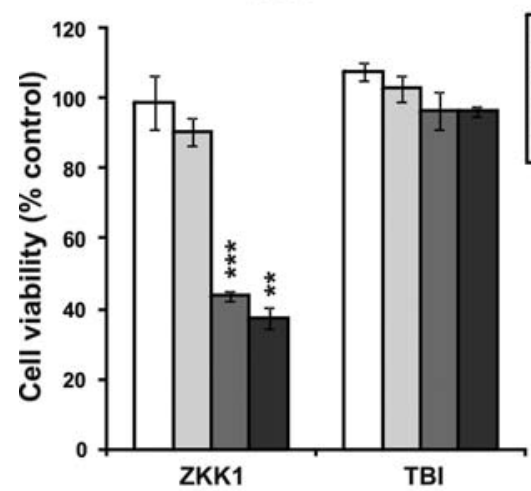

$48 \mathrm{~h}$

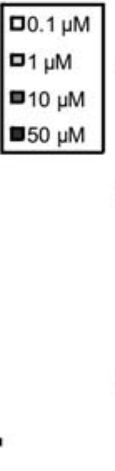

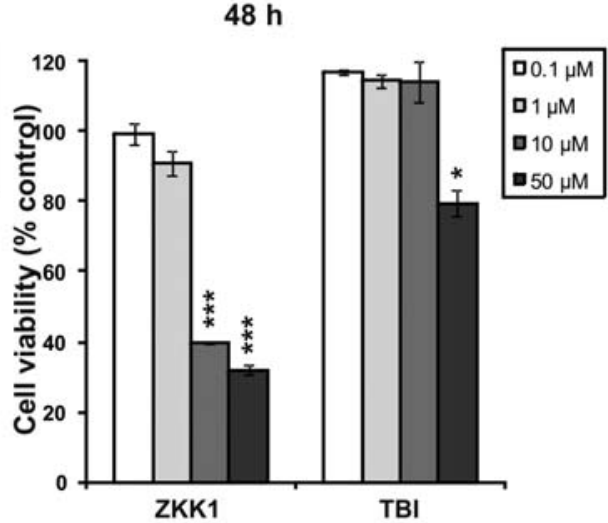

Figure 7. Effects of various CK2 inhibitors on viability of non-transformed astrocytes. Primary glial cultures were developed as described in Materials and methods, and pure astrocytic cultures were kept in the presence of $10 \%$ fetal bovine serum. Cytotoxic effects of TBI and ZKK1 at the concentration range of 0.1-50 $\mu \mathrm{M}$ were determined 24 and $48 \mathrm{~h}$ after the treatment; corresponding doses of DMSO were added to control cultures. MTT metabolism was measured as optical density at $570 \mathrm{~nm}$. Results are expressed in values relative to DMSO-treated, control cells and correspond to the mean \pm SEM of three independent experiments, each in triplicate. Note the relative resistance of non-transformed astrocytes to TBI in contrast to ZKK1.

A

LN229

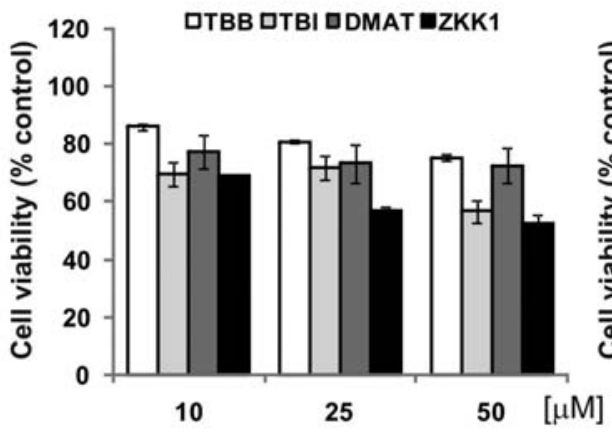

B

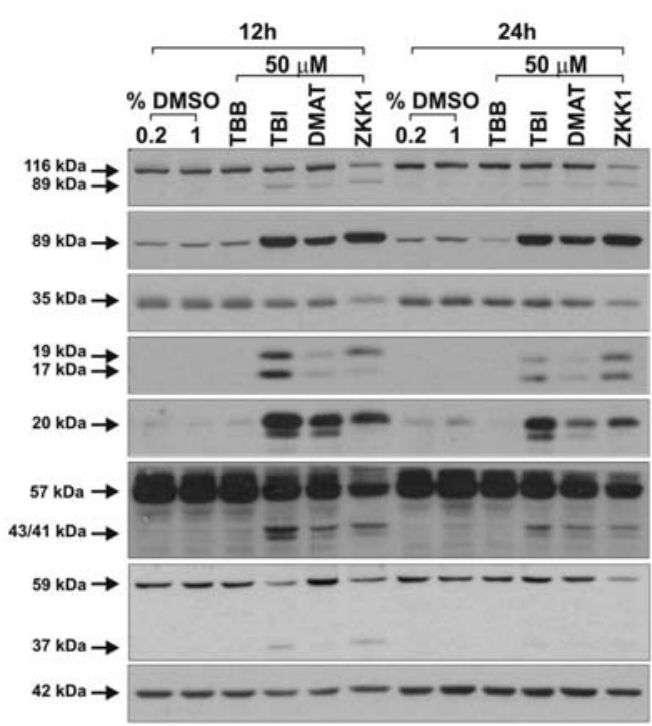

T98G

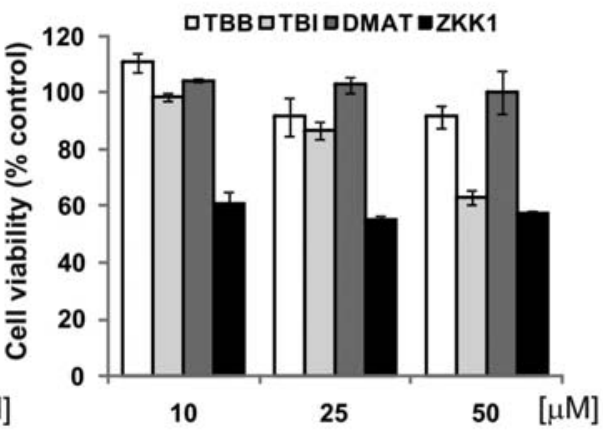

T98G

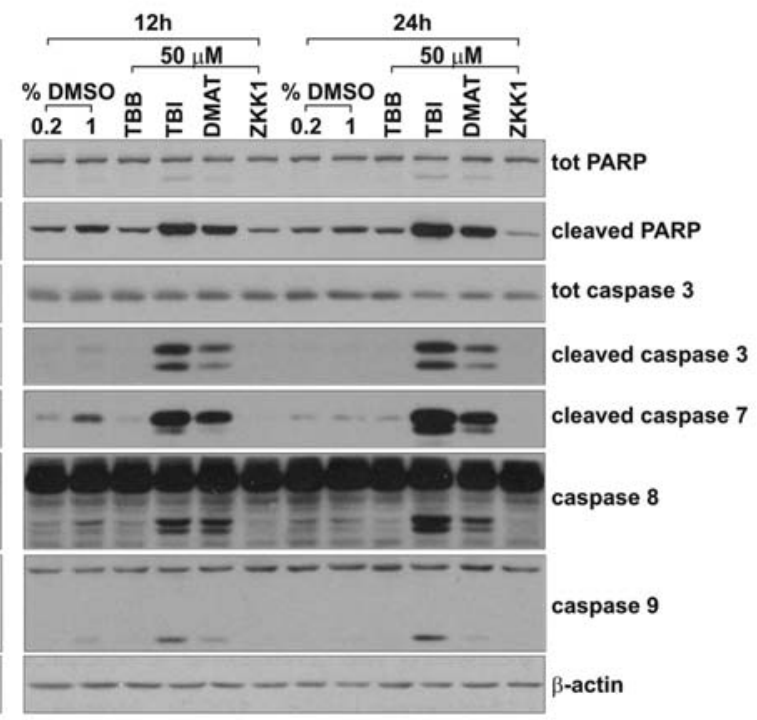

Figure 8. Apoptotic alterations of human malignant glioblastoma cells exposed to TBI and ZKK1. (A) Human malignant glioblastoma T98G and LN229 cells were exposed for $24 \mathrm{~h}$ to TBB, TBI, DMAT or ZKK1, corresponding doses of DMSO were added to control cultures. MTT metabolism was measured as optical density at $570 \mathrm{~nm}$. Results are from a representative experiment, performed in triplicate and are expressed in values relative to DMSO-treated control cells. For TBI and ZKK1 treatment the results were reproduced in three independent experiments and the changes at $50 \mu$ M were highly statistically significant. (B) Representative immunoblots show activation of caspases and PARP proteolysis after drug treatment. Human glioblastoma cells were cultured in the presence of $10 \%$ foetal bovine serum and cytotoxic effects of different compounds were determined 12 and $24 \mathrm{~h}$ after the treatment; 0.2 or $1 \%$ DMSO were added to control cultures. Western blot analysis was performed using antibodies recognizing total and cleaved caspase 8 and 9 , total caspase 3 , cleaved caspase 3 and 7 and total and cleaved PARP. Blots were re-probed with antibody recognizing $\beta$-actin to ensure equal protein loading. 
the initiation of mitochondrial apoptotic pathway. Caspase 9 activation was also observed in LN229 cells exposed to ZKK1. In cultures treated with the compounds, decreased cell viability was accompanied by typical apoptotic changes in cell morphology: retraction of cell extensions, cytoplasm condensation, cell membrane blebbing and formation of apoptotic bodies (not shown).

\section{Discussion}

In the present study we demonstrate for the first time cytotoxic effects of known and recently developed 2-(dimethylamino)-4,5,6,7 tetrabromobenzimidazole (DMAT) and pentabromobenzylisothioureas (ZKK1-8) on cultured rat and human malignant glioma cells. The cytotoxic efficacy of novel compounds DMAT and ZKK1 is higher than the wellknown CK2 inhibitor 4,5,6,7-tetrabromo-1H-benzotriazole (TBB) and is similar to 4,5,6,7 tetrabromo-1H-benzimidazole (TBI). The new compounds were more effective than TBB in induction of growth arrest and cell death in glioma cells. Analysis of caspase cascade activation demonstrated an activation of caspase 3 and 7 followed by PARP cleavage (Figs. 1-3, and 8). The cytotoxic activity of ZKK1 derivatives could be further improved by generation of thiourea derivatives $\mathrm{N}$-substituted with short alkyl groups or an allyl group. The most bulky N-phenyl substituent in thiourea fragment of the molecule reduced cytotoxic activity of the parent compound ZKK1. Isothioureas carrying $\mathrm{Cl}$ or $\mathrm{F}$ substituents on the phenyl ring showed much lower activity than any of the tested drugs from pentabromobenzyl series. The reported data demonstrate that suitably modified tetrabromobenzene molecules may be prospective agents against glioma cells.

Although putative CK2 inhibitors were studied in many different cancer cell lines, a mode and mechanisms of cell death were not evaluated. Kinetics and morphological alterations during CK2 inhibitor-induced cell death as well caspase activation indicated an induction of apoptotic cell death. Caspase activation can be triggered by induction of 'intrinsic' and 'extrinsic' apoptotic pathway, involving the interaction of death ligands with their corresponding death receptors or activation of mitochondrial pathway, respectively (45-47). We demonstrate that cell death induced by ZKK1 and TBI was associated with a disruption of mitochondrial membrane potential, implicating the 'intrinsic' apoptotic pathway in cell death. DMAT upregulated fasL and fas expression and impaired the mitochondrial membrane potential suggesting activation of both receptor-mediated and mitochondria-mediated proteolytic pathways for apoptosis in glioblastoma cells.

Interestingly, TBI and ZKK1 at higher concentration were very effective in the induction of cell death in chemoresistant human glioblastoma cells, even those having mutations in the tumor suppressor PTEN or/and TP53 genes. T98G cells, lacking both functional PTEN and TP53 tumor suppressors, are resistant to most treatments, thus their vulnerability to TBI and ZKK1 suggest an ability to overcome classical drug resistance (Fig. 8). In T98G cells DMAT induced similar activation of caspases 3,7 and 8 as TBI, but without any measurable cytotoxicity. It may indicate that
T98G cells express inhibitors of apoptotic pathway, which are downstream of caspases. The expression of inhibitor of apoptosis proteins (IAPs), which suppress caspase activity, was described in tumor cells (50), including T98G glioblastoma cells expressing large amounts of XIAP, cIAP1 and cIAP2 (51). Another interesting finding is the strong cytotoxic effect of ZKK1 (even at $10 \mu \mathrm{M}$ ) towards T98G cells in the absence of caspase activation, that may suggest the ability to activate programmed, non-apoptotic cell death. ZKK1 activated the caspase cascade in C6 cells having functional PTEN and p53, but not in T98G cells with the mutated tumor suppressors.

TBB, DMAT and ZKK1 impaired cell survival of nontransformed astrocytes at similar concentration range as they did in glioblastoma cells. Only TBI at moderate concentration $(10 \mu \mathrm{M})$ did not affect the viability of non-transformed astrocytes suggesting some specificity toward tumor cells.

Development of CK2 inhibitors resulted in the generation of a number of CK2-directed compounds (reviewed in refs. $8,9,15,25)$. Some of these inhibitors such as 4,5,6,7-tetrabromobenzimidazole (TBI) and 2-dimethylamino-4,5,6,7tetrabromo-1H-benzimidazole (DMAT) inhibited the growth of malignant lymphoblastic leukemia cells with a better efficiency than Imatinib $(17,18)$. Pharmacological downregulation of CK2 activity with specific inhibitors induced cell death in drug resistant R-CEM cells $(19,20)$, human colon cancer cell lines and a breast cancer cell line (21). In the present study we demonstrate that TBI, DMAT and newly synthesized inhibitors MB01-3 and ZKK series have better efficacy towards malignant glioblastoma cells than the previously studied TBB. These inhibitors are cytotoxic at relatively high concentrations but it is well-known that glioblastoma cells have elevated activity of many antiapoptotic and pro-survival signalling pathways resulting in their high resistance to apoptosis inducers.

The exact mechanism by which newly synthesized inhibitors MB01-3 and ZKK series induce apoptosis remains largely unknown. Selectivity is one of the major issues of ATP-competitive inhibitors and it is relevant for the ATPcompetitive inhibitors of CK2 such as TBB, TBI and DMAT $(25,26)$. A study of a panel of 113 kinases revealed that none of the ATP competitive inhibitors in clinical trials or clinically used at the time was totally selective (52). Recent studies by Pagano et al (26) demonstrated that DMAT and its parent compound TBI are potent inhibitors of several other kinases, with a special preference to PIM (provirus integration site for Moloney murine leukaemia virus), PIM2, PIM3, PKD1 (protein kinase D1), HIPK2 (homeodomain-interacting protein kinase 2) and DYRK1a (dual-specificity tyrosinephosphorylated and-regulated kinase 1a). In contrast, TBB is significantly more selective toward CK2, although it also inhibits PIM1 and PIM3 (26).

On the other hand, imatinib mesylate (Gleevec or STI571), the first and probably the best known kinase inhibitor on the market, approved by the FDA 10 May 2001, lacks absolute selectivity. In the present study, TBB which is the most specific CK2 inhibitor known to date, was found to be less effective than other compounds. The concept of 'one drugmany targets' implying that non-specific drugs are sometimes useful and even desirable, is getting recently more 
attention. Thus, a lack of absolute selectivity should not preclude the use of new CK2 inhibitor-based compounds as potential anticancer drugs in preclinical trials and deserves further studies.

\section{Acknowledgements}

This study was supported by grant PBZ-MIN-14/P05/2004 from the Ministry of Science and Higher Education (Poland) and Nencki Institute statutory activity.

\section{References}

1. Louis DN, Ohgaki H, Wiestler OD, Cavenee WK, et al: The 2007 WHO classification of tumours of the central nervous system. Acta Neuropathol 114: 97-109, 2007.

2. Ohgaki H and Kleihaus P: Epidemiology and etiology of gliomas. Acta Neuropathol 109: 93-108, 2005.

3. Smith JS, Tachibana I, Passe SM, Huntley BK, Borell TJ, Iturria N, O'Fallon JR, Schaefer PL, Scheithauer BW, James CD, Buckner JC and Jenkins RB: PTEN mutation, EGFR amplification, and outcome in patients with anaplastic astrocytomas and glioblastoma multiforme. J Natl Cancer Inst 93: 1246-1256, 2001.

4. Smith JS and Jenkins RB: Genetic alterations in adult diffuse glioma: occurrence, significance, and prognostic implications. Front Biosci 5: 213-231, 2000.

5. Simmons ML, Lamborn KR, Takahashi M, Chen P, Israel MA, Berger MS, Godfrey T, Nigro J, Prados M, Chang S, Barker FG and Aldape K: Analysis of complex relationships between age, $\mathrm{p} 53$, epidermal growth factor receptor, and survival in glioblastoma patients. Cancer Res 61: 1122-1128, 2001

6. Zupanska A and Kaminska B: The diversity of p53 mutations among human brain tumors and their functional consequences. Neurochem Int 40: 637-645, 2002.

7. Meggio F and Pinna LA: One-thousand-and-one substrates of protein kinase CK2? FASEB J 17: 349-368, 2003.

8. Litchfield DW: Protein kinase CK2: structure, regulation and role in cellular decisions of life and death. Biochem J 369: 1-15, 2003.

9. Duncan JS and Litchfield DW: Too much of a good thing: the role of protein kinase CK2 in tumorigenesis and prospects for therapeutic inhibition of CK2. Biochim Biophys Acta 1784: 33-47, 2008.

10. Pepperkok R, Lorenz P, Ansorge W and Pyerin W: Casein kinase II is required for transition of G0/G1, early G1, and G1/S phases of the cell cycle. J Biol Chem 269: 6986-6991, 1994.

11. Lorenz P, Pepperkok R and Pyerin W: Requirement of casein kinase 2 for entry into and progression through early phases of the cell cycle. Cell Mol Biol Res 40: 519-527, 1994.

12. Sayed M, Pelech S, Wong C, Marotta A and Salh B: Protein kinase CK2 is involved in G2 arrest and apoptosis following spindle damage in epithelial cells. Oncogene 20: 6994-7005, 2001.

13. Wang H, Davis A, Yu S and Ahmed K: Response of cancer cells to molecular interruption of the CK2 signal. Mol Cell Biochem 227: 167-174, 2001 .

14. Wang G, Unger G, Ahmad KA, Slaton JW and Ahmed K: Downregulation of CK2 induces apoptosis in cancer cells - a potential approach to cancer therapy. Mol Cell Biochem 274: $77-84,2005$

15. Sarno S and Pinna LA: Protein kinase CK2 as druggable target. Mol Biosyst 4: 889-894, 2008.

16. Ruzzene M, Penzo D and Pinna LA: Protein kinase CK2 inhibitor 4, 5, 6, 7-tetrabromobenzotriazole (TBB) induces apoptosis and caspase-dependent degradation of haematopoietic lineage cell-specific protein 1 (HS1) in Jurkat cells. Biochem J 364: 41-47, 2002.

17. Mishra S, Reichert A, Cunnick J, Senadheera D, Hemmeryckx B, Heisterkamp N and Groffen J: Protein kinase CKIIalpha interacts with the Bcr moiety of Bcr/Abl and mediates proliferation of Bcr/Abl-expressing cells. Oncogene 22: 8255-8262, 2003.

18. Mishra S, Pertz V, Zhang B, Kaur P, Shimada H, Groffen J, Kazimierczuk Z, Pinna LA and Heisterkamp N: Treatment of P190 Bcr/Abl lymphoblastic leukemia cells with inhibitors of the serine/ threonine kinase CK2. Leukemia 21: 178-180, 2007.
19. Di Maira G, Brustolon F, Bertacchini J, Tosoni K, Marmiroli S, Pinna LA and Ruzzene M: Pharmacological inhibition of protein kinase CK2 reverts the multidrug resistance phenotype of a CEM cell line characterized by high CK2 level. Oncogene 26: 6915-6926, 2007.

20. Di Maira G, Brustolon F, Tosoni K, Belli S, Krämer SD, Pinna LA and Ruzzene M: Comparative analysis of CK2 expression and function in tumor cell lines displaying sensitivity vs. resistance to chemical induced apoptosis. Mol Cell Biochem 316: 155-161, 2008.

21. Tapia JC, Torres VA, Rodriquez DA, Leyton L and Quest AF: Casein kinase 2 (CK2) increases survivin expression via enhanced beta-catenin-T cell factor/lymphoid enhancer binding factor-dependent transcription. Proc Natl Acad Sci USA 103: 15079-15084, 2006.

22. Hamacher R, Saur D, Fritsch R, Reichert M, Schmid RM and Schneider G: Casein kinase II inhibition induces apoptosis in pancreatic cancer cells. Oncol Rep 18: 695-701, 2007.

23. Hessenauer A, Montenarh M and Gotz C: Inhibition of CK2 activity provokes different responses in hormone-sensitive and hormone-refractory prostate cancer cells. Int J Oncol 22: 1263-1270, 2006.

24. Yde CW, Frogne T, Lykkesfeldt AE, Fichtner I, Issinger OG, and Stenvang J: Induction of cell death in antiestrogen resistant human breast cancer cells by the protein kinase CK2 inhibitor DMAT. Cancer Lett 256: 229-237, 2007.

25. Battistutta R, De Moliner E, Sarno S, Zanotti G and Pinna LA: Structural features underlying selective inhibition of protein kinase CK2 by ATP site-directed tetrabromo-2-benzotriazole. Protein Sci 10: 2200-2206, 2001.

26. Pagano MA, Bain J, Kazimierczuk Z, Sarno S, Ruzzene M, Di Maira G, Elliott M, Orzeszko A, Cozza G, Meggio F and Pinna LA: The selectivity of inhibitors of protein kinase CK2: an update. Biochem J 415: 353-365, 2008.

27. Mazzorana M, Pinna LA and Battistutta R: A structural insight into CK2 inhibition. Cell Biochem 316: 57-62, 2008.

28. Diaz-Nido J, Mizuno K, Nawa H and Marshak DR: Regulation of protein kinase CK2 isoform expression during rat brain development. Cell Mol Biol Res 140: 581-585, 1994.

29. Maccario H, Perera NM, Davidson L, Downes CP and Leslie NR: PTEN is destabilized by phosphorylation on Thr366. Biochem J 405: 439-444, 2007.

30. Bretner M, Najda-Bernatowicz A, Lebska M, Muszynska G, Kilanowicz A and Sapota A: New inhibitors of protein kinase CK2, analogues of benzimidazole and benzotriazole. Mol Cell Biochem 316: 87-89, 2008.

31. Najda-Bernatowicz A, Lebska M, Orzeszko A, Kopanska K, Krzywinska E, Muszynska G and Bretner M: Synthesis of new analogs of benzotriazole, benzimidazole and phthalimidepotential inhibitors of human protein kinase CK2. Bioorg Med Chem 17: 1573-1578, 2009.

32. Zien P, Bretner M, Zastapilo K, Szyszka R and Shugar D: Selectivity of 4, 5, 6, 7-tetrabromobenzimidazole as an ATPcompetitive potent inhibitor of protein kinase CK2 from various sources. Biochem Biophys Res Commun 306: 129-133, 2003.

33. Zien P, Duncan JS, Skierski J, Bretner M, Litchfield DW and Shugar D: Tetrabromobenzotriazole (TBBt) and tetrabromobenzimidazole (TBBz) as selective inhibitors of protein kinase CK2: evaluation of their effects on cells and different molecular forms of human CK2. Biochim Biophys Acta 1754: 271-280, 2005.

34. Pagano MA, Meggio F, Ruzzene M, Andrzejewska M, Kazimierczuk Z and Pinna LA: 2-Dimethylamino-4, 5, 6, 7tetrabromo-1H-benzimidazole: a novel powerful and selective inhibitor of protein kinase CK2. Biochem Biophys Res Commun 321: 1040-1044, 2004.

35. Iwai N, Nagai K and Wachi M: Novel S-benzylisothiourea compound that induces spherical cells in Escherichia coli probably by acting on a rod-shape-determining protein(s) other than penicillin-binding protein 2. Biosci Biotechnol Biochem 66: 2658-2662, 2002.

36. Szydlowska K, Zawadzka M and Kaminska B: Neuroprotectant FK506 inhibits glutamate-induced apoptosis of astrocytes in vitro and in vivo. J Neurochem 99: 965-975, 2006.

37. Ellert-Miklaszewska A, Kaminska B and Konarska L: Cannabinoids down-regulate PI3K/Akt and Erk signalling pathways and activate proapoptotic function of Bad protein. Cell Signal 17: 25-37, 2005.

38. Zupanska A, Dziembowska M, Ellert-Miklaszewska A, Gaweda-Walerych K and Kaminska B: Cyclosporine A induces growth arrest or programmed cell death of human glioma cells. Neurochem Int 47: 430-441, 2005. 
39. Duncan JS, Gyenis L, Lenehan J, Bretner M, Graves LM, Haystead TA and Litchfield DW: An unbiased evaluation of CK2 inhibitors by chemoproteomics: characterization of inhibitor effects on CK2 and identification of novel inhibitor targets. Mol Cell Proteomics 7: 1077-1088, 2008.

40. Khidr L and Chen PL: RB, the conductor that orchestrates life, death and differentiation. Oncogene 25: 5210-5219, 2006.

41. Lundberg AS and Weinberg RA: Functional inactivation of the retinoblastoma protein requires sequential modification by at least two distinct cyclin-cdk complexes. Mol Cell Biol 18: 753-761, 1998.

42. Salvesen GS and Dixit VM: Caspase activation: the inducedproximity model. Proc Natl Acad Sci USA 96: 10964-10967, 1999.

43. Bao Q and Shi Y: Apoptosome: a platform for the activation of initiator caspases. Cell Death Differ 14: 56-65, 2007.

44. Riedl SJ and Salvesen GS: The apoptosome: signalling platform of cell death. Nat Rev Mol Cell Biol 8: 405-413, 2007.

45. Ashkenazi A and Dixit VM: Death receptors: signaling and modulation. Science 281: 1305-1308, 1998

46. Reed J: Apoptosis-based therapies. Nat Rev Drug Discov: 111-121, 2002.
47. Kroemer G and Reed JC: Mitochondrial control of cell death. Nat Med 6: 513-519, 2000

48. Steinbach JP and Weller M: Apoptosis in gliomas: molecular mechanisms and therapeutic implications. J Neurooncol 70: 245-254, 2004

49. Ziegler DS, Kung AL and Kieran MW: Anti-apoptosis mechanisms in malignant gliomas. J Clin Oncol 26: 493-500, 2008.

50. LaCasse EC, Mahoney DJ, Cheung HH, Plenchette S, Baird S and Korneluk RG: IAP-targeted therapies for cancer. Oncogene 27: 6252-6275, 2008

51. Li L, Thomas RM, Suzuki H, De Brabander JK, Wang X and Harran PG: A small molecule Smac mimic potentiates TRAILand TNFalpha-mediated cell death. Science 305: 1471-1474, 2004.

52. Fabian MA, Biggs WH III, Treiber DK, et al: A small moleculekinase interaction map for clinical kinase inhibitors. Nat Biotechnol 23: 329-336, 2005. 